Original Research Paper

\title{
Recovery of Manganese from Zinc Smelter Slag
}

\author{
${ }^{1}$ Rasoul Khosravi, ${ }^{2}$ Rasoul Fatahi, ${ }^{3}$ Hossein Siavoshi and ${ }^{3}$ Fatemeh Molaei \\ ${ }^{I}$ Department of Mining Engineering, University of Lorestan, Khoram Abad, Iran \\ ${ }^{2}$ Department of Mining Engineering, University of Tehran, Tehran, Iran \\ ${ }^{3}$ Department of Mining and Geological Engineering, University of Arizona, Arizona, USA
}

\author{
Article history \\ Received: 14-09-2020 \\ Revised: 23-11-2020 \\ Accepted: $30-11-2020$ \\ Corresponding Author: \\ Hossein Siavoshi \\ Department of Mining and \\ Geological Engineering, \\ University of Arizona, Arizona, \\ USA \\ Email: Hosseinsiavoshi@email.arizona.edu
}

\begin{abstract}
Using a software-based experiment design, the application of the leaching process for the extraction of manganese from Zinc Plant Slag (ZPS) was investigated. In this study, the effect of different parameters, i.e., $\mathrm{H}_{2} \mathrm{SO}_{4}$ concentration, pulp density, agitation rate, temperature and reaction time, was investigated. Response Surface Methodology (RSM) based on the Central Composite Design (CCD) has been implemented to consider the main parameters. A hydrometallurgical route to manganese silicate from spent zinc plant residue has been proposed in this investigation. Based on the investigation, Mn can be extracted from ZPS in sulfuric acid without any oxidant agents. The results showed that the optimum conditions of this study are an $\mathrm{H}_{2} \mathrm{SO}_{4}$ concentration of $2 \mathrm{~mol} / \mathrm{L}$ and a solid/liquid ratio of $0.07 \mathrm{~g} / \mathrm{mL}$ at $50^{\circ} \mathrm{C}$ for $150 \mathrm{~min}$ and an agitation speed of $1000 \mathrm{rpm}$. A manganese leaching efficiency higher than $83 \%$ is reached under these conditions, with a corresponding $22 \%$ iron, $23 \%$ lead, $68 \%$ zinc and $65 \%$ aluminum.
\end{abstract}

Keywords: Manganese, Zinc, Acid Leaching, Slag, Precipitation

\section{Introduction}

Manganese is one of the most widely used metals in the world, ranking fourth after iron, aluminum and copper (Charef et al., 2017), which is used in various fields including steel production, batteries, nonferrous metallurgy and fine chemicals (Aksoy and Sagol, 2016; Alaoui et al., 2016). In steelmaking processes either indirectly through ferroalloys production or directly in pig iron, manganese has a substantial role that cannot be substituted with any other compound. For a long time, the unequal distribution of global manganese resources has been acknowledged as a problem for the United States and other industrialized countries with insufficient domestic resources to supply their markets. Consequently, it would be advantageous to look for more available sources of manganese to support the supply of this commodity in the event of future supply disruptions (Schulz et al., 2018).

The continuous loss of natural resources, increasing energy prices and tight environmental restrictions also lead to expanded metal recovery efforts (Ghosh et al., 2016; Shen et al., 2007; Xin et al., 2011). The development of a competent and cost-effective extractive method is now awaiting low-grade ores in millions of tons (Ghosh et al., 2016; Pradhan et al., 2006) (Arsent'ev et al., 1991). High-grade manganese ore resources $(>40 \%)$ are typically used to produce metallic alloys by pyrometallurgical processes as they are more readily available for this process (Aslan, 2007). Moreover, hydrometallurgical methods have also been introduced widely to extract $\mathrm{Mn}$ from low-grade ores, residuals and other secondary sources. There are several reports on leaching of low-grade manganese from carbonate and silicate ores, which mainly include direct acid leaching, pre-roasting followed by acid or water leaching, reductive acid leaching and electrochemical leaching. To recover manganese from the aforementioned manganese minerals, several acid leaching processes have been developed (Arsent'ev et al., 1991; Ghassa et al. 2017; Genuino et al., 2018). Comba et al. (1991) proposed an efficient leaching method for manganese-bearing silicates $\left(\mathrm{MnSiO}_{3}\right.$ and $\left[(\mathrm{Mn}, \mathrm{Fe}) \mathrm{SiO}_{3}\right]$ as major phases) using $\mathrm{HCl}$ and $\mathrm{CaF}_{2}$. Where a countercurrent leaching procedure was introduced to extract $\mathrm{Mn}$ along with $\mathrm{CaF}_{2}(99 \%)$ as a byproduct. In another study, Mn leaching recovery of above $90 \%$ with sulfuric acid (80 wt.\%) in 90 min was reported (Charef et al., 2017).

In the case of common-occurring manganese oxide mineral (e.g., $\mathrm{MnO}_{2}$ ), $\mathrm{Mn}$ of higher oxidation state, i.e., $\mathrm{Mn}$ (IV), must first be reduced to $\mathrm{MnO}$, which then can be leached in a dilute acid solution (Li et al., 2017). Two methods have been suggested for this purpose: 
1) Hydro reduction in the presence of various chemical reducing agents (Lin et al., 2016; Mohanty et al., 2017; Reuter et al., 2004)

2) Pyro-reduction at high temperature (Wasserstein and Lazar, 2016)

Slags are generated in various pyrometallurgical processes, including pretreatments in metals extraction, refining and alloying, which usually consist of a combination of oxides, sulfides, elemental metals and silicate minerals. During these processes, huge amounts of slags are generally produced and disposed of to process tailings. Due to their metal content, slags also are of great environmental concern, control of which imposes an extra cost to the process. Recycling of the by-product slags is an attractive alternative for reducing or eliminating the disposal costs and environmental drawbacks, which to some extent, saves resources as well. Based on the origin and properties of the slags, recycling techniques are classified for three main slag categories, i.e., ferrous, nonferrous and incineration (Chandra et al., 2011; Chen et al., 2017). Zinc slag, which is produced in zinc roasting plants, can be considered as a valuable secondary source for $\mathrm{Mn}$ recovery. While landfill disposal of this waste can have a detrimental impact on the environment due to the high concentration of heavy metals, proper recovery of these elements from zinc slag can provide economic benefits. Zinc sulfide mineral (sphalerite) is one of the most important commodities for $\mathrm{Zn}$ production. More than $80 \%$ of zinc is produced by hydrometallurgical treatment of $\mathrm{ZnS}$ in the Roast-Leach-Electrowinning (RLE) process (Xue et al., 2016). Sphalerite should be roasted at high temperatures (up to $1100^{\circ} \mathrm{C}$ ) in the presence of carbon to produce acid-soluble Zinc calcine $(\mathrm{ZnO})$ following the reaction (1) (Cai et al., 2013):

$2 \mathrm{ZnS}+3 \mathrm{O}_{2}=2 \mathrm{ZnO}+2 \mathrm{SO}_{2}+\Delta \mathrm{H}$

At this temperature during roasting, slag will be formed, which contains an elevated concentration of light metals (such as silicon, iron, manganese, calcium and aluminum) in various forms. Manganese is one of the most important metals enriched in zinc slag.

In this study, the effect of various parameters at different conditions on leaching recovery of $\mathrm{Mn}$ from zinc slag using sulfuric acid is investigated. The optimum leaching conditions and a mathematical model (based on central composite design methodology) for manganese extraction are presented and discussed in detail.

\section{Materials and Methods}

\section{Slag Sample}

The slag sample was obtained from a zinc-lead roasting plant, located in Yazd, Iran. After size reduction, the $-20 \mathrm{~mm}$ sulfide minerals (mostly sphalerite and galena) are charged to a rotary kiln in the presence of coking coal. The mineral/coke ratio is fixed on $7 / 3$ and minerals are roasted at $1100^{\circ} \mathrm{C}$. The produced soluble calcine is then used for $\mathrm{Zn}$ production and the generated black slag is disposed of to the tailing dam. Representative samples were collected from the tailing to study the potential extraction of valuable metals. The fine particles fuse, making coarser slag particles during the roasting at elevated temperatures. Further size reduction consisting of jaw and cone crushers followed by a ball mill was used for grinding the slag sample to the particle size of below $75 \mu \mathrm{m}$. The chemical composition of the slag sample used in this study was determined by the X-Ray Fluorescence (XRF) and is given in Table 1 and Fig. 1.

The Atomic Absorption Spectroscopy (AAS) (Agilent VGA 77) analysis also indicated that the slag sample contains $10.47 \%$ manganese. In addition, Si, Fe, Al and $\mathrm{Ca}$ were found to be the primary constituents in their oxide forms. Moreover, XRD analysis revealed the patterns of tephroite $\left(\mathrm{Mn}_{2} \mathrm{SiO}_{4}\right)$, fayalite $\left(\mathrm{Fe}_{2} \mathrm{SiO}_{4}\right)$ and wurtzite $(\mathrm{ZnS})$ in the sample. Quartz, dolomite, feldspar group (calcium and potassium groups) and an amorphous phase (perhaps the fused silicate) were also detected in the slag sample at varying but not major extents.

\section{Acid Leaching}

The leaching tests were carried out in a $500 \mathrm{~mL}$ glass reactor heated on a hot plate equipped with a digital controlled stirrer and a temperature regulation thermometer for various conditions on representative samples. The effect of five different parameters, including acid concentration, solid/liquid ratio of pulp, agitation rate, temperature and reaction time was investigated. The leaching solution was prepared using distilled water and the analytical grade $\mathrm{H}_{2} \mathrm{SO}_{4}$ at target concentrations. The amount of solution was calculated based on the desired solid/liquid ratio and first added to the system. When the solution reached the required temperature, $5 \mathrm{~g}$ of slag sample was added into the glass reactor and the pulp was stirred at a certain rate. After leaching, the Pregnant Leach Solution (PLS) was analyzed for its content of the elements of interest using the AAS analysis and Total Reflection X-Ray Fluorescence (TXRF) (GNR-TX2000, Italy). The metals recoveries were calculated according to Equation 2:

$R=\frac{C_{1} V}{C_{0} m} \times 100$

where, $R$ is the metal recovery (\%), $C_{1}$ is the $\mathrm{Mn}$ concentration in PLS (mg/l), $V$ is the leachate volume, $C_{0}$ is the concentration of $\mathrm{Mn}$ in feed slag sample $(\mathrm{mg} / \mathrm{kg})$ and $m$ is the mass of feed slag (kg) (Charef et al., 2017). 


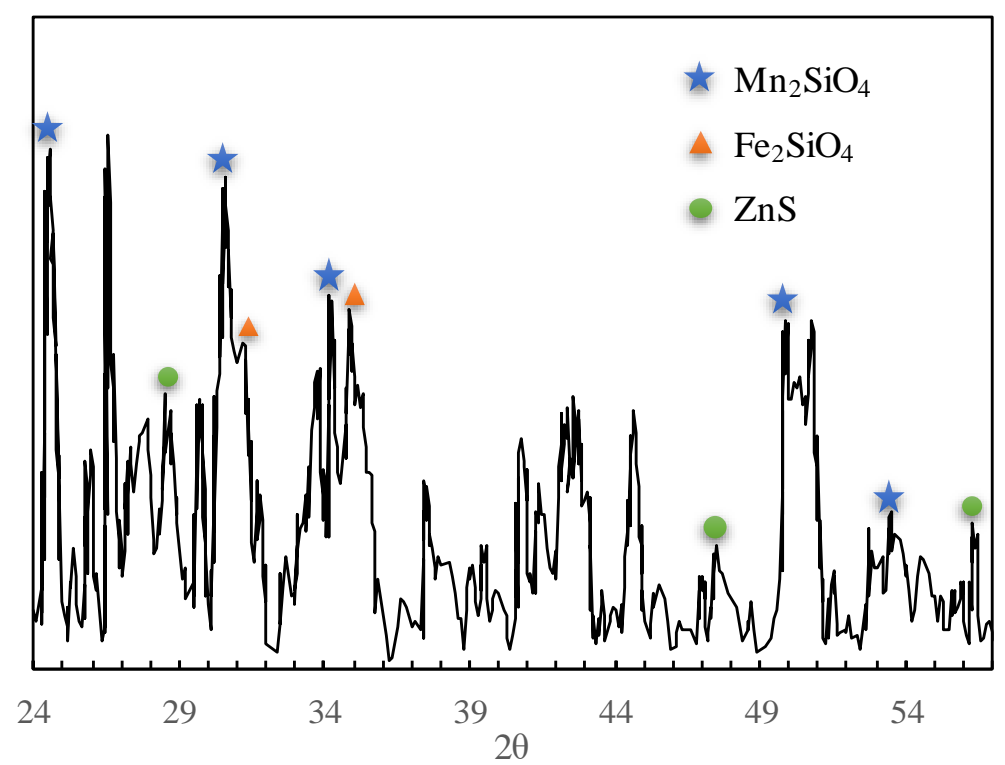

Fig. 1: XRD pattern of slag sample

Table 1: Chemical analysis of slag sample (mass fraction)

\begin{tabular}{llllll}
\hline Composition & $\mathrm{SiO}_{2}$ & $\mathrm{MnO}$ & $\mathrm{Fe}_{2} \mathrm{O}_{3}$ & $\mathrm{Al}_{2} \mathrm{O}_{3}$ & $\mathrm{CaO}$ \\
\hline Content $(\%)$ & 29.92 & 13.52 & 17.77 & 9.67 & 16.44 \\
\hline
\end{tabular}

Table 2: Independent variables and their levels for CCD

\begin{tabular}{|c|c|c|c|c|c|c|}
\hline \multirow[b]{2}{*}{ Independent variable } & & \multicolumn{5}{|c|}{ Actual values and coded levels } \\
\hline & & $-\alpha$ & -1 & 0 & +1 & $+\alpha$ \\
\hline Sulfuric acid concentration (M) & $\mathrm{A}$ & 0.50 & 1.00 & 1.50 & 2.00 & 2.50 \\
\hline Stirring speed (rpm) & $\mathrm{B}$ & 400.00 & 600.00 & 800.00 & 1000.00 & 1200.00 \\
\hline Temperature (C) & $\mathrm{C}$ & 40.00 & 50.00 & 60.00 & 70.00 & 80.00 \\
\hline Leching time (min) & $\mathrm{D}$ & 60.00 & 90.00 & 120.00 & 150.00 & 180.00 \\
\hline Solid/Liquid ratio & $\mathrm{E}$ & 0.01 & 0.03 & 0.05 & 0.07 & 0.09 \\
\hline
\end{tabular}

Once the optimum conditions were decided for the leaching experiments, the PLS from the optimum condition experiment was used for Mn recovery through precipitation. For this purpose, the $\mathrm{pH}$ of the system was increased to 5.5 using $\mathrm{Na}_{2} \mathrm{~S}$ (analytical grade) to precipitate iron in the form of $\mathrm{FeOH}_{2}$ (Ghassa et al., 2017) as well as Al and Zn. The PLS was then filtered to separate the precipitated iron. The $\mathrm{pH}$ of the filtrate increased again to 8.5 to precipitate out the manganese. The precipitates were analyzed by XRD to characterize the final products. The metal content was also analyzed to calculate extraction recovery efficiency.

\section{Optimization Model}

Response Surface Methodology (RSM) based on the Central Composite Design (CCD) was utilized to study and optimize the effects of different factors on $\mathrm{Mn}$ recovery using Design-Expert software (Demo v.7.0, Stat-Ease Inc.). RSM is a rigorous mathematical tool for modeling and evaluating problems where the response is influenced by many factors and the main motivation is to get an optimum response (Khosravi et al., 2017). CCD was conducted by five factors using 42 tests and 8 replicates at the center points. The $\alpha$ was selected at 2 . The ranges and the levels of the factors investigated in the model are given in Table 2.

\section{Results}

\section{Leaching and Precipitation}

Leaching efficiency of $\mathrm{Mn}$ as a function of time was investigated for various parameters, i.e., acid concentration, temperature, solid/liquid ratio and stirring rate. Results for the effect of various parameters on the recovery of $\mathrm{Mn}$ from the slag 
sample are given in Fig. 2. Although the solid/liquid ratio was found to have a positive effect on the
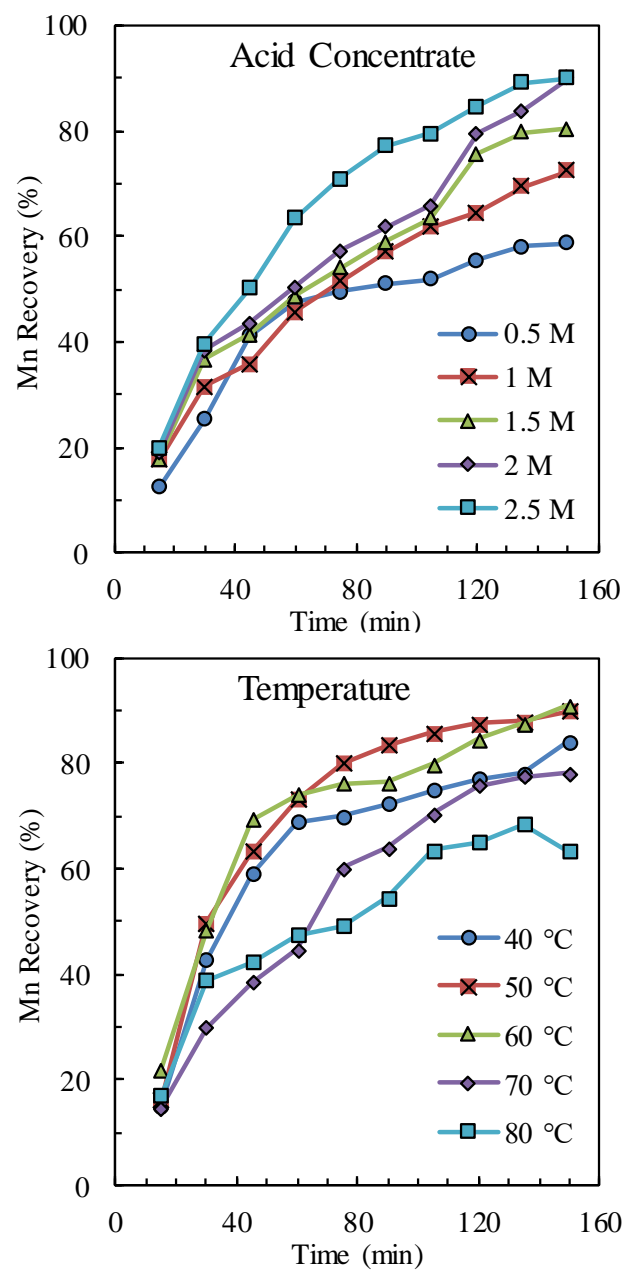

recovery of $\mathrm{Mn}$ from slag, the temperature shows a varying impact on the recovery.
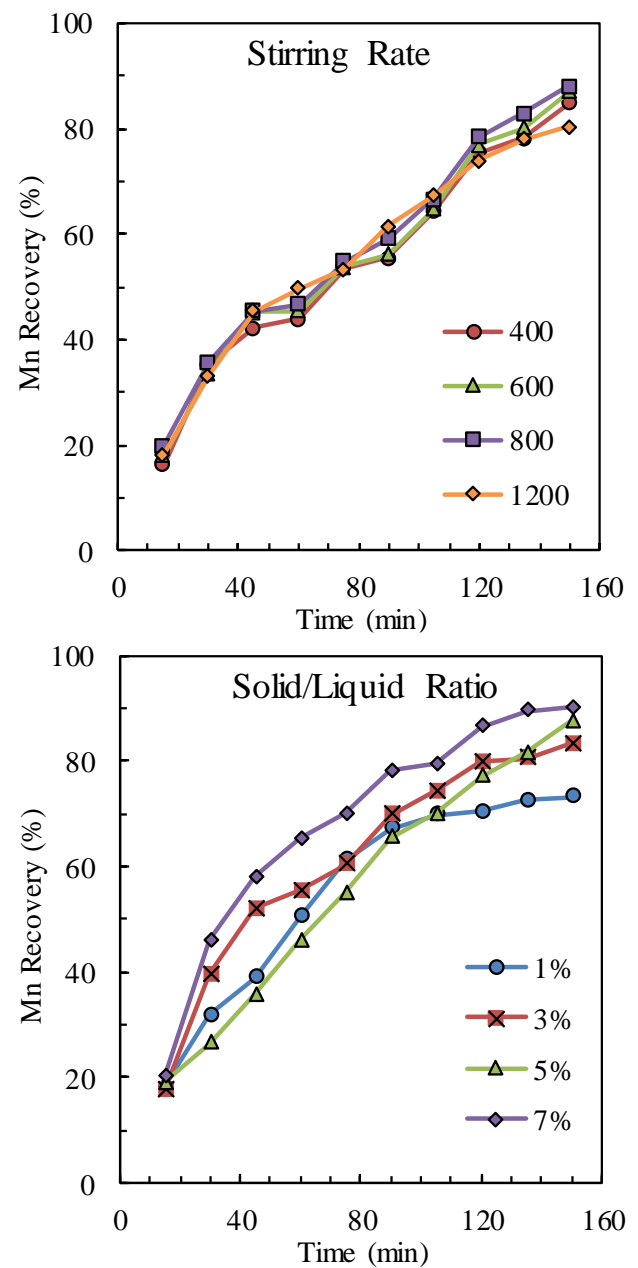

Fig. 2: Effect of various parameters on the recovery of Mn from slag as a function of time
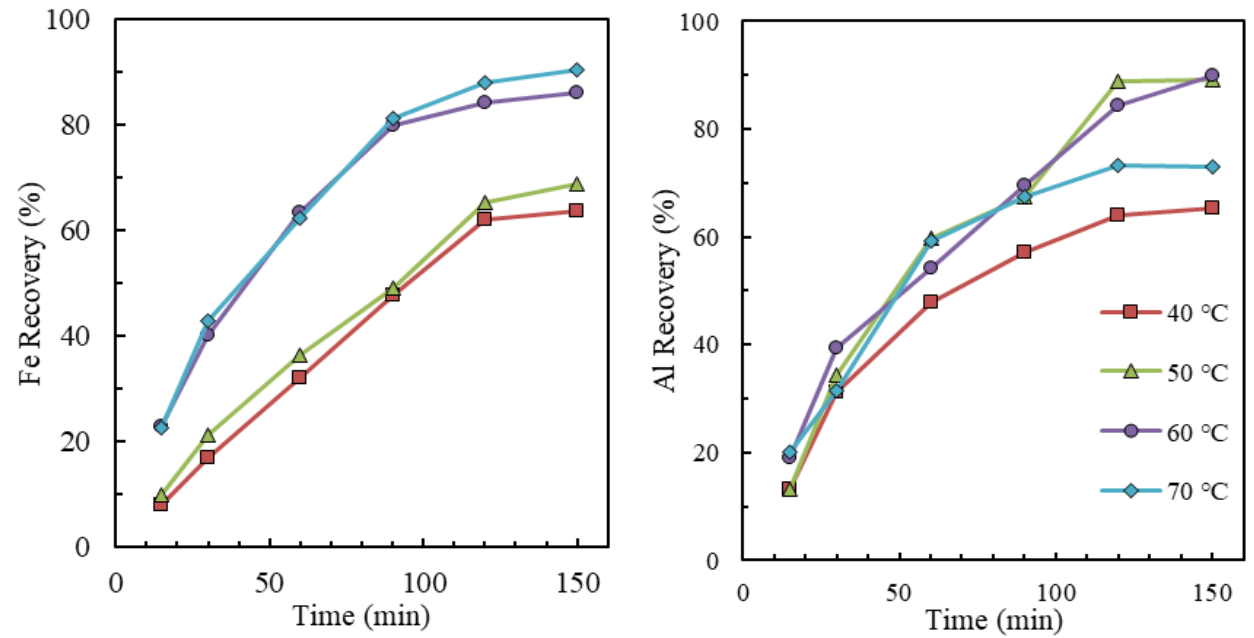

Fig. 3: Effect of temperature on the recovery of $\mathrm{Fe}$ (left) and $\mathrm{Al}$ (right) from slag as a function of time 
It was found that the $\mathrm{Mn}$ recovery increases by increasing temperature from $40^{\circ} \mathrm{C}$ up to $60^{\circ} \mathrm{C}$. Figure 3 shows the recovery of two other major elements (i.e., $\mathrm{Fe}$ and $\mathrm{Al}$ ) from the slag as a function of temperature. It can be seen from the figure that recovery of both $\mathrm{Al}$ and $\mathrm{Fe}$ increases rapidly at $60^{\circ} \mathrm{C}$, while that of $\mathrm{Fe}$ is significantly higher. Although the recovery of $\mathrm{Al}$ seems to slightly decrease by a further increase in the temperature, the recovery of Fe remains unchanged after this point. This finding coincides well with previous reports (Liu et al., 2009; Yang et al., 2015). Considering the amount of $\mathrm{Al}_{2} \mathrm{O}_{3}$ and $\mathrm{Fe}_{2} \mathrm{O}_{3}$ and significant recovery of the two elements, it can be concluded that the higher recovery of these reactions hurts the recovery of $\mathrm{Mn}$ after $60^{\circ} \mathrm{C}$.

After acid leaching, precipitation experiments were conducted at different $\mathrm{pH}$ values to selectively recover the $\mathrm{Mn}$ from the PLS. After each $\mathrm{pH}$ adjustment, the precipitates were filtered and the filtrate solution was analyzed by AAS for the metal content to determine the recovery of the metals. Figure 4 shows the $\mathrm{Mn}, \mathrm{Zn}, \mathrm{Fe}$, $\mathrm{Al}$ and $\mathrm{Pb}$ precipitation yields as a function of solution $\mathrm{pH}$ adjusted with $\mathrm{Na}_{2} \mathrm{~S}$. It was observed that the target elements start to form precipitates in less than $5 \mathrm{~min}$ during the precipitation experiments. As it is expected, the precipitation rate increased with increasing $\mathrm{pH}$. The manganese was precipitated at $\mathrm{pH} 8.5$, while $\mathrm{Zn}, \mathrm{Fe}, \mathrm{Al}$ were all precipitated at lower $\mathrm{pH}$ values of 2 to 6 . Lead, however, mainly remained in the solution even after $\mathrm{Mn}$ precipitation at $\mathrm{pH} 8-8.5$. This pattern agrees with the previously reported works for the selective separation of $\mathrm{Zn}$ from $\mathrm{Mn}$ at $\mathrm{pH} 2$ (Fattahi et al., 2016). Therefore, it would be wise to purify manganese sulfate solutions by selectively precipitating the other metals as metal-sulfides at lower pH values (Bryson and Bijsterveld, 1991).

Table 3: Proposed empirical model and ANOVA results for Manganese recoveries

\begin{tabular}{|c|c|c|c|c|c|c|}
\hline Source & Sum of squares & $\mathrm{df}$ & Mean square & f-value & $\mathrm{p}$-value & \\
\hline Model & 15905.97 & 7 & 2272.28 & 40.44 & $<0.0001$ & Significant \\
\hline A & 10764.3 & 1 & 10764.3 & 191.58 & $<0.0001$ & - \\
\hline B & 694.06 & 1 & 694.06 & 12.35 & 0.0011 & - \\
\hline $\mathrm{C}$ & 1170.08 & 1 & 1170.08 & 20.82 & $<0.0001$ & - \\
\hline $\mathrm{D}$ & 935.48 & 1 & 935.48 & 16.65 & 0.0002 & - \\
\hline $\mathrm{E}$ & 392.63 & 1 & 392.63 & 6.99 & 0.0115 & - \\
\hline $\mathrm{AC}$ & 1158.01 & 1 & 1158.01 & 20.61 & $<0.0001$ & - \\
\hline $\mathrm{C}^{2}$ & 791.42 & 1 & 791.42 & 14.08 & 0.0005 & - \\
\hline Residual & 2359.82 & 42 & 56.19 & - & - & - \\
\hline Lack of fit & 1688.71 & 35 & 48.25 & 0.50 & 0.9150 & Not significant \\
\hline Pure error & 671.19 & 7 & 95.88 & - & - & - \\
\hline Core total & 18265.87 & 49 & - & - & - & - \\
\hline
\end{tabular}

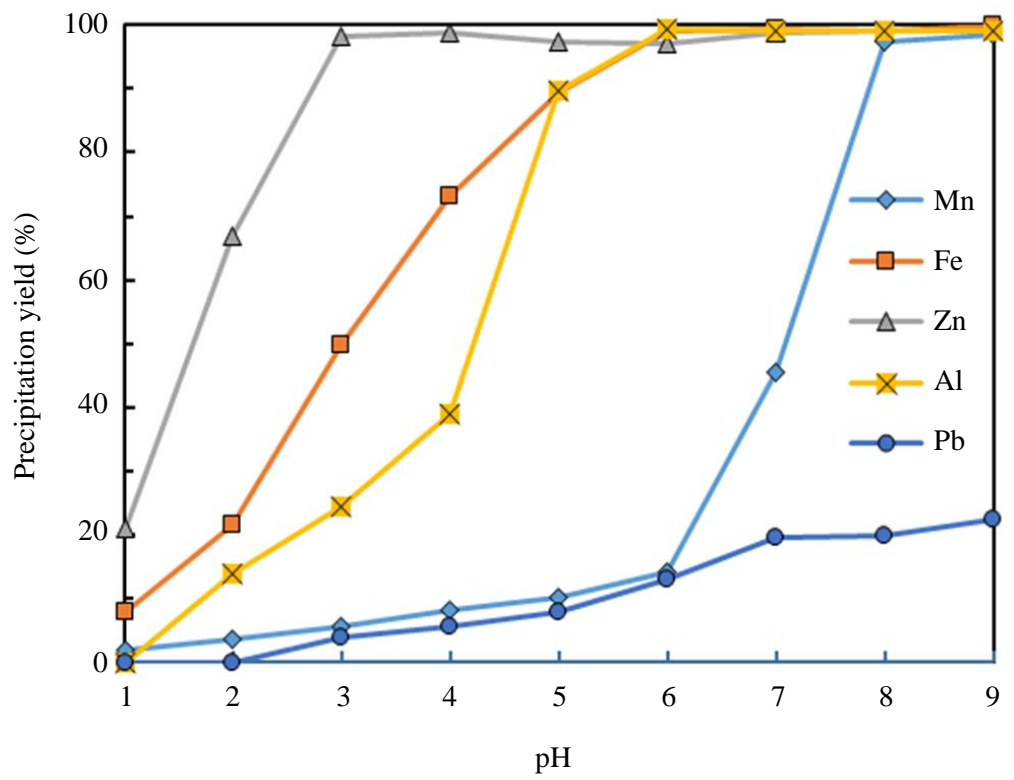

Fig. 4: Precipitation of $\mathrm{Mn}, \mathrm{Fe}, \mathrm{Al}, \mathrm{Zn}, \mathrm{Al}$ and $\mathrm{Pb}$ with $\mathrm{Na}_{2} \mathrm{~S}$ at different $\mathrm{pH}$ solutions 


\section{Leaching Optimization}

All experiments were designed and analyzed using the Design Expert 7 Trial version (State Ease, Inc., Minneapolis, MN, USA). Central composite experimental design and response data (metals recoveries) are presented in Table 3. Different mathematical models have been fitted to metal recoveries to find the best model. According to Table 3, the mathematical model has a P-value lower than 0.0001, which confirms that models are significant.

As a function of acid concentration (A), stirring intensity (B), temperature (C) and leaching period (D), the final equation describing manganese Recovery $(R)$ in terms of coded factors were obtained:

$$
\begin{aligned}
& R=-291.56+104.97(A)+0.02(B)+7.23(C) \\
& +9.67(D)+156.65(E)-1.2(A)(C)-0.05(C)^{2}
\end{aligned}
$$

The ANOVA confirmed that the equation accurately represented the true relationship between the manganese recovery ratio and the significant variables. The value of $40.44 \mathrm{~F}$ indicates the model was substantial. The small $F$ and large $P(\mathrm{P}>0.05)$ fit shortage values mean that the model is appropriate to predict the manganese recovery rate.

Effects of surface plots of variables and 3D response in Fig. 5 display the perturbation plots of the impact of the key factors on the manganese leaching intensity, simulated in Table 3. At a given point in the design space, these plots help to compare the influence of all the variables. A steep slope or curvature of a factor means that the performance of leaching is sensitive to that factor. Figure 5a-5f) specifies the $3 \mathrm{D}$ response surface graphs for the relationship between two factors and when the other two factors were held at their center levels of the manganese leaching rate.

Figure $5 b, c$ and d illustrate that manganese leaching recovery increases meaningfully and linearly with increasing the solution acid concentration, solid to liquid and leaching time. It is also noted that in the original phases, the leaching rate rises quickly with an increase in contact moment and then gradually decreases (Figs. 5c and 5d). It's also observed from Fig. 5 That acid concentration is the most important variable and plays a significant part in the leaching method (Figs. 5b, d and e).

Increasing the dose of sulfuric acid increased their leaching rate. The quadratic impact of stirring speed was statistically important, but in practice, it did not have important impacts on manganese leaching (Figs. 5b and 5f). As observed, the decrease in the manganese dissolution occurs at low and high levels of temperature (Figs. 5a, e and f). While the rise in acid concentration value leads to a slight rise in manganese leaching at all concentrations of stirring speed and solid to fluid, it did not have a significant rise. As the acid concentration was increased from 0.5 to $2.5 \mathrm{~mol} / \mathrm{L}$, the leaching amount of manganese dissolution increased.
By using design-expert software, the dissolution recovery efficiency of manganese from the slag solution was optimized to achieve maximum dissolution recovery. Figure 6 indicates the trend towards the optimum point in the motion factor. Moving the parameters into the optimum point decreased the recovery of manganese, as shown. The optimum process parameters were two molars for acid concentration, $2.5 \mathrm{~h}$ for leaching time, $1000 \mathrm{rpm}$ for stirring speed and $0.07 \mathrm{~g} / \mathrm{L}$ for solid to liquid. Under these circumstances, the manganese dissolution effectiveness was approximately $91 \%$. It can be discovered in Fig. 6 that the ranking of important variables is as follows: $\mathrm{A}>\mathrm{D}>\mathrm{C}>\mathrm{B}$. Besides, 3D response surface plots were used to obtain a clearer knowledge of the impact of variables on manganese regeneration as shown in Fig. 6. These plots provided data on the main effect of four variables. Figure 7 presents the correlation between acid leaching experimental data and the model data. The correlation coefficient (0.87) shows that the experimental test validates the proposed model.

\section{Leaching Thermodynamics}

According to XRD analysis, the manganese orthosilicate mineral, tephroite $\left(\mathrm{Mn}_{2} \mathrm{SiO}_{4}\right)$ is the main mineral containing $\mathrm{Mn}$ in the ZPS. To the best of our knowledge, this mineral is not reported as the containing Mn mineral in ZPS; hence no literature was found in terms of its extraction as a secondary source. The chemical reaction for the dissolution of tephroite in an acidic medium is given in Equation 3:

$$
\begin{aligned}
& \mathrm{Mn}_{2} \mathrm{SiO}_{4}+4 \mathrm{H}^{+} \rightarrow 2 \mathrm{Mn}^{2+}+\mathrm{H}_{4} \mathrm{SiO}_{4} \\
& \Delta G_{r}^{0}=156.47 \frac{\mathrm{kJ}}{\mathrm{mol}}
\end{aligned}
$$

The equilibrium is constant for Equation 3 can be redefined as Equation 4, which combined with Equation 5 will lead to Equation 6:

$$
\begin{aligned}
& k=\left[M n^{2+}\right]^{2} /\left[H^{+}\right]^{4} \\
& p H=-\log \left[H^{+}\right] \\
& \log k=2 \log \left[M^{2+}\right]+4 p H
\end{aligned}
$$

Thus, the ion concentration of $\mathrm{Mn}^{2+}$ can be calculated from Equation 7:

$$
\left[M n^{2+}\right]=10^{\left(\frac{1}{2} \log k-2 p H\right)}
$$

where, $\log k$ can be calculated from the equation $\Delta G_{r}^{\circ}$ $=-2.303 \mathrm{RT} \log k$. The dissolution of manganese depends on the equilibrium constant and $\mathrm{pH}$ based on 
Equation 5. Manganese in tephroite exists as $\mathrm{Mn}^{2+}$ $\left(2 \mathrm{MnO} . \mathrm{SiO}_{2}\right)$, unlike another commercial mineral (e.g., pyrolusite), which contains insoluble $\mathrm{MnO}_{2}$. Acid leaching is carried out directly for minerals containing $\mathrm{MnO}$, while treatment by reduction roasting followed by acid leaching (Feng et al., 2013;
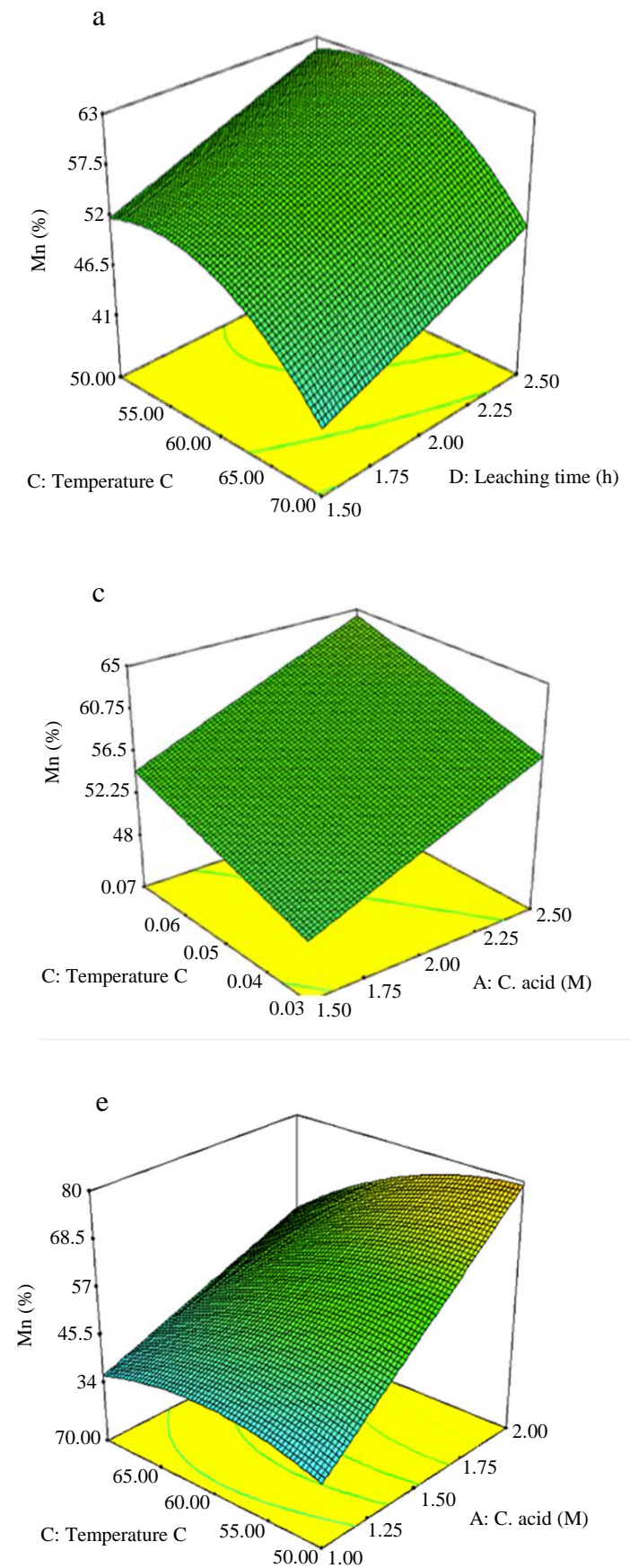

Yang et al., 2013; Zhang et al., 2013; Zhao et al., 2010) or direct reductive leaching with various reducing agents such as hydrogen peroxide (El Hazek et al., 2006; Nayl et al., 2011) oxalic acid (Sahoo et al., 2001) and sulfur dioxide (Sun et al., 2013) is employed for obtaining manganese from $\mathrm{MnO}_{2}$.
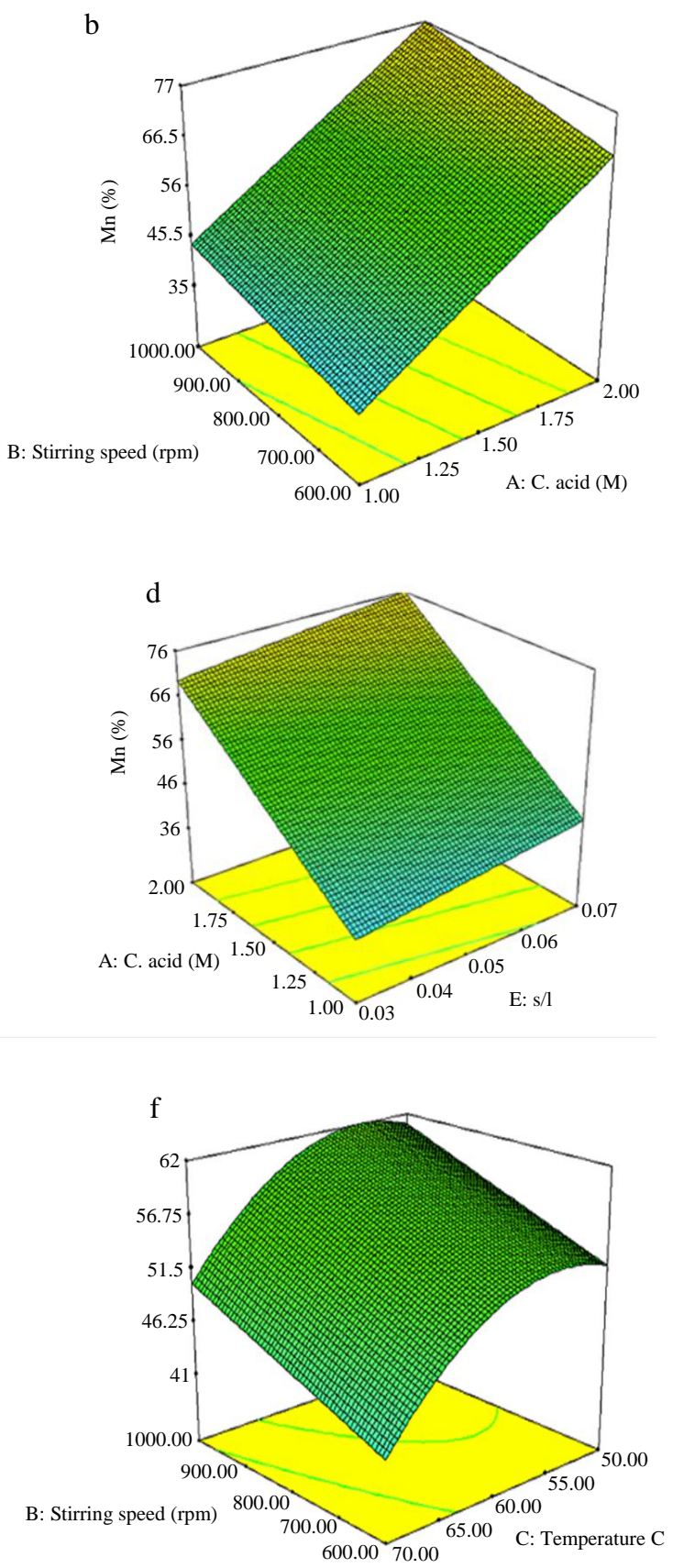

Fig. 5: 3D surface response plots showing the impact of two variables on manganese recovery percentage: (a) Temperature and leaching time; (b) stirring speed and acid concentration; (c) solid to liquid and leaching time; (d) acid concentration and solid to liquid; (e) temperature and acid concentration; (f) stirring speed and temperature 

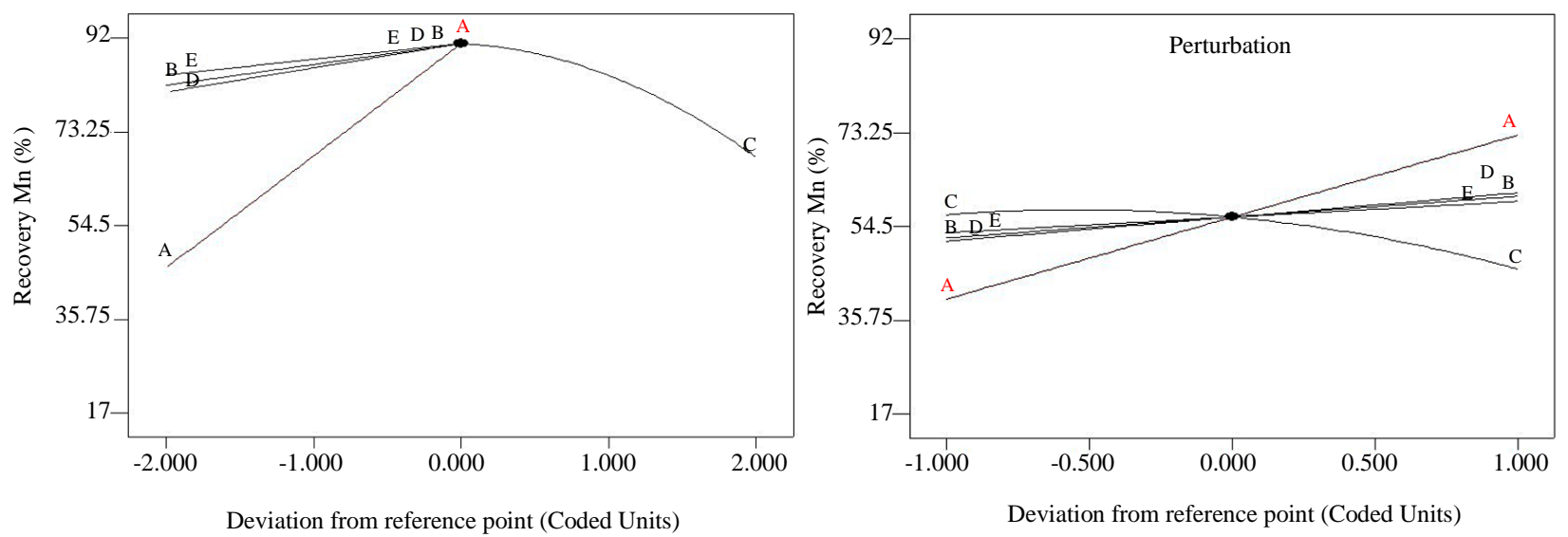

Fig. 6: Left: Perturbation plot showing the relative significance of factors on Mn recovery percentage, right: Perturbation plot showing the optimal conditions of factors to obtain the maximum recovery percentage of manganese

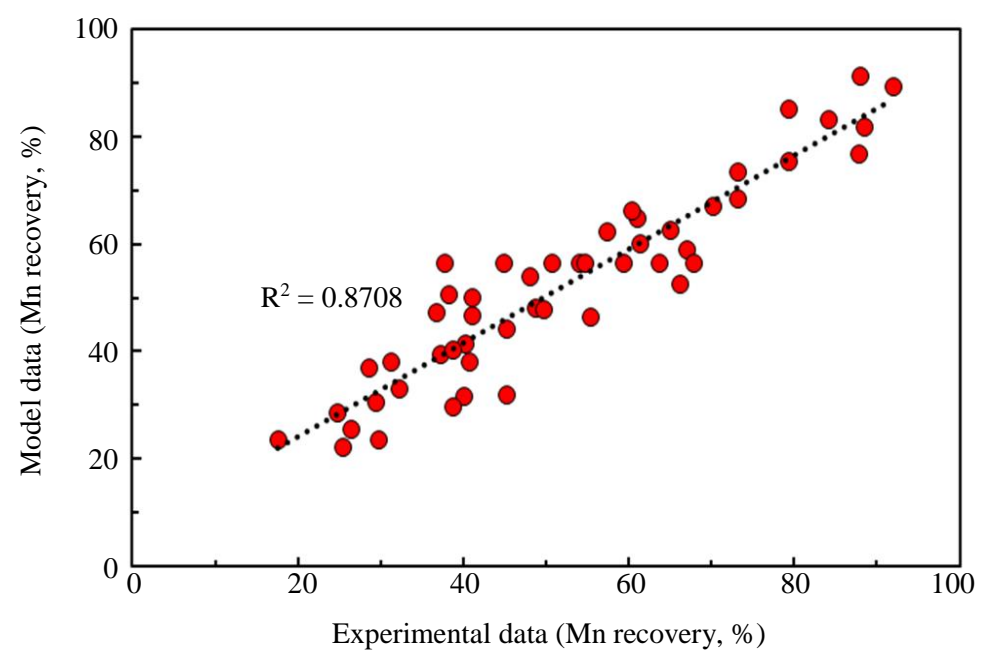

Fig. 7: Model versus experimental data correlation for Mn leaching

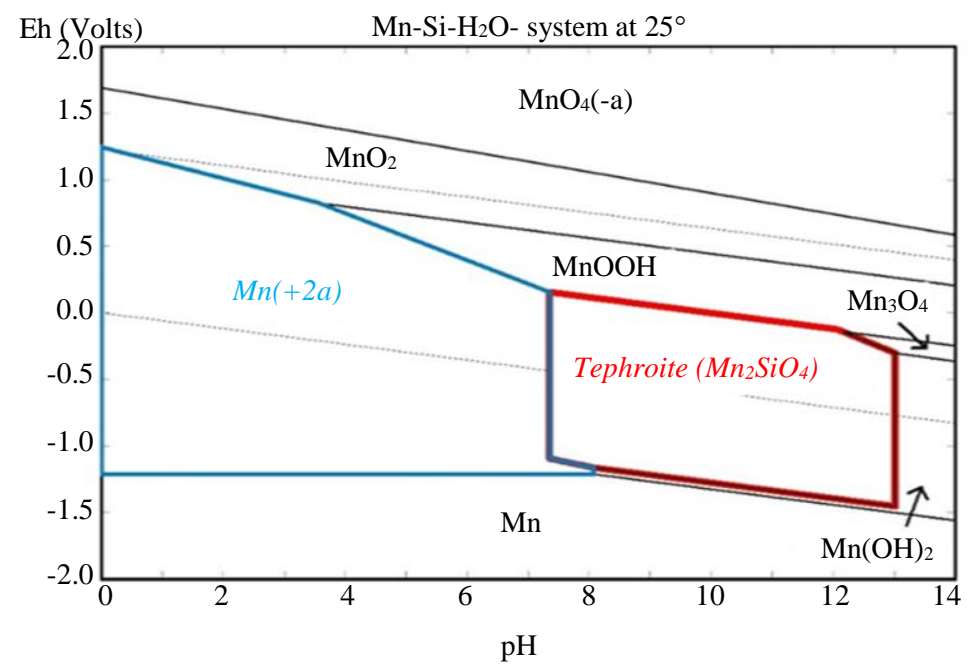

Fig. 8: Eh-pH diagram of the $\mathrm{Mn}-\mathrm{Si}-\mathrm{H}_{2} \mathrm{O}$ thermodynamic system at $25^{\circ} \mathrm{C}$ drawn by $\mathrm{HSC} 6.0$ chemistry software. The concentration of $\mathrm{Mn}$ and $\mathrm{Si}$ is equal to 0.1 molars 
The Eh-pH diagram is established for the Mn-Si- $\mathrm{H}_{2} \mathrm{O}$ system at $25^{\circ} \mathrm{C}$ to provide a better understanding of mineral dissolution and oxide formations boundaries using HSC 6.0 chemistry software (Outokumpu Research, Finland). The dotted lines in Fig. 8 represent the stability region of $\mathrm{H}_{2} \mathrm{O}$. As can be seen from Fig. 8, $\mathrm{Mn}$ is stable in the wide range of $\mathrm{pH}$ and potential in the forms of $\mathrm{MnO}_{2}, \mathrm{MnOOH}, \mathrm{Mn}_{3} \mathrm{O}_{4}, \mathrm{Mn}_{2} \mathrm{SiO}_{4}, \mathrm{Mn}(\mathrm{OH})_{2}$ and $\mathrm{Mn}$. The dissolution of tephroite has been controlled by both potential and $\mathrm{pH}$. When $\mathrm{pH}$ falls from neutral to acid region in almost a wide window of $\mathrm{Eh}, \mathrm{Mn}^{2+}$ is stable, denoting the dissolution of the mineral. Hydrogen ions contributed to metal dissolution (Equation 3 and Fig. 8). The system of $\mathrm{Mn}-\mathrm{Si}-\mathrm{S}-\mathrm{H}_{2} \mathrm{O}$ was drawn by the same software as well as Spana software (Royal Institute of Technology, Sweden), but no other species were found to coordinate to the metal. When in acidic media, the Eh of the system is too high (more than $1.2 \mathrm{~V}$ ) or too low (less than $-1.2 \mathrm{~V}$ ), $\mathrm{Mn}^{2+}$ will convert to more stable species of $\mathrm{MnO}_{2}$ and $\mathrm{Mn}$, respectively.

\section{Discussion}

The recovery of $\mathrm{Mn}$ increases by increasing acid concentration as a function of time. On the other hand, it was found that the recovery of $\mathrm{Mn}$ is not significantly affected by the stirring rate. This indicates that the convection through the system has a minor effect on the Mn leaching. After $60^{\circ} \mathrm{C}$, the recovery of Mn decreased by increasing temperature up to $80^{\circ} \mathrm{C}$. One possible reason for this discrepancy can be the presence of other compounds in the slag, which may start to consume the acid at higher temperatures. The proposed mathematical models for the prediction of metal recoveries were shown in Table 3. The results indicated that data should transform to square root format for zinc and lead recoveries to achieve the most significant model; while mathematical models for other metals did not need any transformation-data gathered from different mathematical models (Linear, 2FI, quadratic and cubic) as well as Variance Analysis (ANOVA) showed that manganese dissolution was best described with a quadratic model. In addition, by adding the dose of sulfuric acid the leaching rate increases.

Beside aforementioned, although the Mn surface stays in the divalent oxidation state over a wide range of natural water conditions, higher oxidation states may be reached by the metal and the net surface chemistry can be influenced by such oxidation.

Finally, when in acidic media, the Eh of the system is too high (more than 1.2 V) or too low (less than $-1.2 \mathrm{~V}$ ), $\mathrm{Mn}^{2+}$ will convert to more stable species of $\mathrm{MnO}_{2}$ and $\mathrm{Mn}$, respectively.

\section{Conclusion}

A hydrometallurgical route to manganese silicate from spent zinc plant residue has been proposed in this investigation. The results have shown the route is technically viable to treat this kind of residue. Manganese can be extracted from ZPS ore in sulfuric acid medium.

Also, the results of leaching tests showed that manganese is effectively recovered and reached a maximum of $91.95 \%$. To determine, model and optimize the influential variables, a response surface method using a central composite design was implemented. The optimum conditions for this leaching are an $\mathrm{H}_{2} \mathrm{SO}_{4}$ concentration of $2 \mathrm{~mol} / \mathrm{L}$ and a solid/liquid ratio of 0.07 $\mathrm{g} / \mathrm{mL}$ at $50^{\circ} \mathrm{C}$ for $150 \mathrm{~min}$ and an Agitation speed of $1000 \mathrm{rpm}$. Under these conditions, a manganese leaching efficiency greater than $91.16 \%$ is achieved, with a corresponding extraction of iron $22 \%$, lead $23 \%$, zinc $68 \%$ and aluminum $64 \%$.

In addition, a quadratic model was developed to explain the behavior of the manganese mechanism of recovery. By Analysis Of Variance (ANOVA), the importance of independent variables was evaluated.

Besides, according to XRD analysis, the manganese orthosilicate mineral, tephroite $\left(\mathrm{Mn}_{2} \mathrm{SiO}_{4}\right)$ is the main mineral containing $\mathrm{Mn}$ in the ZPS.

Furthermore, when $\mathrm{pH}$ falls from neutral to an acid region in almost a wide window of $\mathrm{Eh}, \mathrm{Mn}^{2+}$ is stable, denoting the dissolution of the mineral. Hydrogen ions contributed to metal dissolution.

\section{Acknowledgment}

The authors would like to express their special thanks of gratitude to Behzad Vaziri Hassas and Mehdi Abad company for providing the slag sample and also the management of the Central Laboratory of Lorestan University for providing valuable comments.

The author, Fatemeh Molaei, wishes to express her thanks for the financial support of Freeport McMoRan Inc. in her education. The authors sincerely appreciate all valuable comments and suggestions provided by the reviewers of the journal, which helped to improve the quality of the paper.

\section{Author's Contributions}

Rasoul Khosravi: Is the idea owner, did the primary lab tests and data analysis.

Rasoul Fatahi: Did lab works and financial support.

Hossein Siavoshi: Did idea development, design the figures and writing manuscript.

Fatemeh Molaei: Was in charge of overall direction, planning and manuscript writing.

\section{Ethics}

This article is original and contains unpublished material. The corresponding author confirms that all of the other authors have read and approved the manuscript and no ethical issues involved. 


\section{References}

Aksoy, D. O., \& Sagol, E. (2016). Application of central composite design method to coal flotation: Modelling, optimization and verification. Fuel, 183, 609-616.

Alaoui, A., EL Kacemi, K., EL Ass, K., Darmane, Y., \& Kitane, S. (2016). Kinetic study of the leaching of manganese mine tailings by organic reductant in sulphuric acid solution. Mineral Processing and Extractive Metallurgy, 125(2), 109-116.

Arsent'ev, V. A., Yavorskaya, G. M., \& Kovaleva, O. V. (1991). Manganese recovery from oxide ores by leaching with acid. SU Patent, (1624038).

Aslan, N. (2007). Application of response surface methodology and central composite rotatable design for modeling the influence of some operating variables of a Multi-Gravity Separator for coal cleaning. Fuel, 86(5-6), 769-776.

Bryson, A. W., \& Bijsterveld, C. H. (1991). Kinetics of the precipitation of manganese and cobalt sulphides in the purification of a manganese sulphate electrolyte. Hydrometallurgy, 27(1), 75-84.

Cai, Z., Feng, Y., Li, H., Du, Z., \& Liu, X. (2013). Corecovery of manganese from low-grade pyrolusite and vanadium from stone coal using fluidized roasting coupling technology. Hydrometallurgy, 131, 40-45.

Chandra, N., Amritphale, S. S., \& Pal, D. (2011). Manganese recovery from secondary resources: A green process for carbothermal reduction and leaching of manganese bearing hazardous waste. Journal of hazardous materials, 186(1), 293-299.

Charef, S. A., Affoune, A. M., Caballero, A., CruzYusta, M., \& Morales, J. (2017). Simultaneous recovery of $\mathrm{Zn}$ and $\mathrm{Mn}$ from used batteries in acidic and alkaline mediums: A comparative study. Waste Management, 68, 518-526.

Chen, J., Li, L., Chen, G., Peng, J., \& Srinivasakannan, C. (2017). Rapid thermal decomposition of manganese ore using microwave heating. Journal of Alloys and Compounds, 699, 430-435.

Comba, P., Lei, K. P., \& Carnahan, T. G. (1991). CaF2enhanced HC1 Leaching of a Manganese-bearing Silicate Ore (Vol. 9372). US Department of the Interior, Bureau of Mines.

El Hazek, M. N., Lasheen, T. A., \& Helal, A. S. (2006). Reductive leaching of manganese from low grade Sinai ore in $\mathrm{HCl}$ using $\mathrm{H} 2 \mathrm{O} 2$ as reductant. Hydrometallurgy, 84(3-4), 187-191.

Fattahi, A., Rashchi, F., \& Abkhoshk, E. (2016). Reductive leaching of zinc, cobalt and manganese from zinc plant residue. Hydrometallurgy, 161, 185-192.

Feng, Y. L., Cai, Z. L., Li, H. R., Du, Z. W., \& Liu, X. W. (2013). Fluidized roasting reduction kinetics of low-grade pyrolusite coupling with pretreatment of stone coal. International Journal of Minerals, Metallurgy and Materials, 20(3), 221-227.
Genuino, D. A. D., de Luna, M. D. G., \& Capareda, S. C. (2018). Improving the surface properties of municipal solid waste-derived pyrolysis biochar by chemical and thermal activation: Optimization of process parameters and environmental application. Waste Management, 72, 255-264.

Ghassa, S., Noaparast, M., Shafaei, S. Z., Abdollahi, H., Gharabaghi, M., \& Boruomand, Z. (2017). A study on the zinc sulfide dissolution kinetics with biological and chemical ferric reagents. Hydrometallurgy, 171, 362-373.

Ghosh, S., Mohanty, S., Akcil, A., Sukla, L. B., \& Das, A. P. (2016). A greener approach for resource recycling: Manganese bioleaching. Chemosphere, 154, 628-639.

Khosravi, R., Azizi, A., Ghaedrahmati, R., Gupta, V. K., \& Agarwal, S. (2017). Adsorption of gold from cyanide leaching solution onto activated carbon originating from coconut shell-Optimization, kinetics and equilibrium studies. Journal of industrial and engineering chemistry, 54, 464-471.

Li, Q., Rao, X. F., Xu, B., Yang, Y. B., Liu, T., Jiang, T., \& Hu, L. (2017). Extraction of manganese and zinc from their compound ore by reductive acid leaching. Transactions of Nonferrous Metals Society of China, 27(5), 1172-1179.

Lin, Q. Q., Gu, G. H., Wang, H., Zhu, R. F., Liu, Y. C., \& Fu, J. G. (2016). Preparation of manganese sulfate from low-grade manganese carbonate ores by sulfuric acid leaching. International Journal of Minerals, Metallurgy and Materials, 23(5), 491-500.

Liu, Z. R., Zeng, K., Zhao, W., \& Li, Y. (2009). Effect of temperature on iron leaching from bauxite residue by sulfuric acid. Bulletin of environmental contamination and toxicology, 82(1), 55-58.

Mohanty, S., Ghosh, S., Nayak, S., \& Das, A. P. (2017). Bioleaching of manganese by Aspergillus sp. isolated from mining deposits. Chemosphere, 172, 302-309.

Nayl, A. A., Ismail, I. M., \& Aly, H. F. (2011). Recovery of pure $\mathrm{MnSO} 4 \cdot \mathrm{H} 2 \mathrm{O}$ by reductive leaching of manganese from pyrolusite ore by sulfuric acid and hydrogen peroxide. International Journal of Mineral Processing, 100(3-4), 116-123.

Pradhan, N., Das, B., Gahan, C. S., Kar, R. N., \& Sukla, L. B. (2006). Beneficiation of iron ore slime using Aspergillus niger and Bacillus circulans. Bioresource technology, 97(15), 1876-1879.

Reuter, M., Xiao, Y., \& Boin, U. (2004, January). Recycling and environmental issues of metallurgical slags and salt fluxes. In VII International conference on molten slags fluxes and salts, The South African Institute of Mining and Metallurgy (Vol. 2004, pp. 349-356). 
Sahoo, R. N., Naik, P. K., \& Das, S. C. (2001). Leaching of manganese from low-grade manganese ore using oxalic acid as reductant in sulphuric acid solution. Hydrometallurgy, 62(3), 157-163.

Schulz, K. J., DeYoung, J. H., Seal, R. R., \& Bradley, D. C. (Eds.). (2018). Critical mineral resources of the United States: economic and environmental geology and prospects for future supply. Geological Survey.

Shen, R., Zhang, G., Dell'Amico, M., Brown, P., \& Ostrovski, O. (2007). A feasibility study of recycling of manganese furnace dust.

Sun, W. Y., Su, S. J., Wang, Q. Y., \& Ding, S. L. (2013). Lab-scale circulation process of electrolytic manganese production with low-grade pyrolusite leaching by SO2. Hydrometallurgy, 133, 118-125.

Wasserstein, R. L., \& Lazar, N. A. (2016). The ASA statement on p-values: context, process and purpose.

Xin, B., Chen, B., Duan, N., \& Zhou, C. (2011). Extraction of manganese from electrolytic manganese residue by bioleaching. Bioresource technology, 102(2), 1683-1687.
Xue, J., Zhong, H., Wang, S., Li, C., Li, J., \& Wu, F. (2016). Kinetics of reduction leaching of manganese dioxide ore with Phytolacca americana in sulfuric acid solution. Journal of Saudi Chemical Society, 20(4), 437-442.

Yang, K. D., Ye, X. J., Jing, S. U., Su, H. F., Long, Y. F., LÜ, X. Y., \& Wen, Y. X. (2013). Response surface optimization of process parameters for reduction roasting of low-grade pyrolusite by bagasse. Transactions of Nonferrous Metals Society of China, 23(2), 548-555.

Yang, Y., Wang, X., Wang, M., Wang, H., \& Xian, P. (2015). Recovery of iron from red mud by selective leach with oxalic acid. Hydrometallurgy, 157, 239-245.

Zhang, Y., You, Z., Li, G., \& Jiang, T. (2013). Manganese extraction by sulfur-based reduction roasting-acid leaching from low-grade manganese oxide ores. Hydrometallurgy, 133, 126-132.

Zhao, Y., Zhu, G., \& Cheng, Z. (2010). Thermal analysis and kinetic modeling of manganese oxide ore reduction using biomass straw as reductant. Hydrometallurgy, 105(1-2), 96-102. 